\title{
Jogos Educacionais Digitais como Ferramentas de Apoio à Capacitação Discente na Identificação de Fake News Escritas em Língua Portuguesa: Um Estudo de Caso
}

\author{
Claudio A. Passos ${ }^{1}$, Flávio R. M. da Silva ${ }^{1}$, Isabel Fernandes ${ }^{2}$, \\ Paulo M. S. Freire ${ }^{1}$, Ronaldo R. Goldschmidt ${ }^{1}$ \\ ${ }^{1}$ Instituto Militar de Engenharia (IME) \\ Rio de Janeiro - RJ - Brasil \\ ${ }^{2}$ Centro Universitário Uniamérica \\ Foz do Iguaçu - PR - Brasil \\ \{claudio, flavio.matias, paulomsfreire, ronaldor.gold\}eime.eb.br \\ isabel@uniamerica.br
}

\begin{abstract}
The fake news problem has become serious and concerned modern society. One of the strategies to combat this kind of news is to train people to identify them. Although there are initiatives where such training is supported by digital educational games (DEGs), the DEGs used do not have Portuguesewritten news. To fill this gap, this article proposes a version of the "Game of the Trail" that exercises the identification of fake news written in Portuguese, in addition to offering support for mining data about the performance of its players. A case study involving forty-three high school students revealed evidence that the proposed DEG contributed to student training in identifying fake news.
\end{abstract}

Resumo. O problema das fake news tem preocupado os mais diversos segmentos sociais. Uma das estratégias para combater essas notícias é capacitar pessoas para identificá-las. Embora existam iniciativas em que tal capacitação é apoiada por jogos educacionais digitais (JED), os JED utilizados não dispõem de notícias escritas em Língua Portuguesa. Para suprir esta lacuna, o presente artigo propõe uma versão do "Jogo da Trilha" que exercita a identificação de fake news escritas em Português, além de oferecer suporte para mineração de dados sobre o desempenho de seus jogadores. Um estudo de caso com quarenta e três alunos de ensino médio revelou evidências de que o JED proposto contribuiu para a capacitação discente na identificação de fake news.

\section{Introdução}

O problema de combater fake news (i.e., notícias falsas divulgadas de forma intencional) não é recente [Freire and Goldschmidt 2019]. Contudo, sua complexidade vem aumentando em função do crescimento do volume e da velocidade de divulgação dessas notícias proporcionado pelos meios digitais de divulgação de notícias (MDDN), em especial, por redes sociais virtuais (RSV) [Shu et al. 2017], tais como Twitter e Facebook.

Como exemplo do poder de influência das fake news, pode-se enfatizar o caso da pandemia de COVID-19 (Coronavirus Disease-19) que matou centenas de milhares de 
pessoas no ano de 2020 ao redor do mundo ${ }^{1}$, onde inúmeras fake news têm sido divulgadas em MDDN [Mejova and Kalimeri 2020]. Tais divulgações têm dificultado, de forma significativa, o esclarecimento da população sobre a disseminação da pandemia e sobre as medidas de enfrentamento da doença a serem adotadas.

Diferentes segmentos da sociedade têm pesquisado como combater fake news disponibilizadas em MDDN, em especial nas RSV [Zhou et al. 2019]. Como consequência, algumas ações mitigadoras estão sendo potencializadas, onde pode-se destacar a criação de legislação punitiva ${ }^{2}$, os serviços de checagem de fatos e o emprego de abordagens computacionais nos MDDN [Freire and Goldschmidt 2020].

Apesar da importância dessas ações que objetivam enfraquecer a divulgação das fake news, uma das principais estratégias de combate a esse tipo danoso de notícia é pelo desenvolvimento, na sociedade, de uma capacidade crítica (isenta de preconceitos, ideologias e interesses) que possibilite uma melhor distinção entre as informações verdadeiras e falsas nos meios digitais [UNESCO 2019]. Uma das principais formas de prover tal capacidade, assim como enfatizar a preocupação em divulgar somente informações verificadamente verdadeiras, é por meio de iniciativas educacionais. Segundo [UNESCO 2016], tais iniciativas educacionais estão presentes na alfabetização midiática e informacional, onde um de seus principais objetivos é capacitar as pessoas para avaliar criticamente os conteúdos digitais. Neste contexto de alfabetização, merecem destaque os jogos educacionais digitais (JED) que, conforme indicado por [Paz et al. 2018], têm sido adotados como ferramentas de apoio ao aprendizado, nos diferentes níveis de ensino.

Embora existam estudos voltados à experimentação de JED como instrumentos de capacitação de pessoas na identificação de fake news, até onde foi possível observar, os JED utilizados não dispõem de notícias escritas em Língua Portuguesa. Diante deste cenário, pode-se levantar a seguinte questão de pesquisa: JED podem ser utilizados para capacitação discente na identificação de fake news escritas em Português?

Assim sendo, o presente trabalho teve como objetivo buscar evidências experimentais que respondessem positivamente à questão de pesquisa levantada. Para tanto, propôs o JED "Jogo da Trilha" adaptado para o problema de identificação de fake news escritas em Língua Portuguesa. Com acesso a uma base de notícias reais e falsas atualizada de forma contínua ao longo do tempo, o jogo estimula os alunos a se manterem informados sobre atualidades do mundo contemporâneo, ao mesmo tempo em que exercita a capacidade crítica dos discentes na identificação de notícias falsas. O referido JED foi concebido de forma a coletar dados sobre o desempenho de seus usuários a fim de permitir, por meio de técnicas de mineração de dados, um acompanhamento longitudinal individual e em grupo desses usuários. Para demonstrar a viabilidade do jogo diante do problema de se identificar fake news em Língua Portuguesa foi realizado um estudo de caso com quarenta e três alunos do ensino médio de uma escola da rede privada de educação do município de Foz do Iguaçu-PR. Os resultados obtidos no estudo de caso revelaram evidências de que o JED não somente contribuiu para a capacitação discente na identificação de fake news, como também foi bem avaliado pelos estudantes, como demonstrado a partir de pesquisa de opinião acerca da qualidade do jogo.

\footnotetext{
${ }^{1}$ www. who. int/emergencies/diseases/novel-coronavirus-2019

${ }^{2}$ https://www12.senado.leg.br/noticias/materias/2020/06/02/nova-versao-de-lei-contra-fake-news-terarestricoes-a-contas-anonimas-e-mais-poder-a-denuncias-de-usuarios
} 
Este artigo está organizado em mais cinco seções. A Seção 2 descreve os principais trabalhos relacionados com o tema desta pesquisa. O "Jogo da Trilha" é apresentado na Seção 3 e o estudo de caso realizado a partir desse jogo é exposto na Seção 4, detalhando a metodologia utilizada e os principais resultados obtidos. Por fim, a Seção 5 destaca as contribuições e os principais resultados obtidos pelo presente trabalho.

\section{Trabalhos Relacionados}

Os trabalhos relacionados a este estudo podem ser divididos em dois grupos. O primeiro é composto por quatro trabalhos baseados no apoio educacional no tocante ao combate às fake news. Em [Francesco and Leone 2020], discute-se como a aplicação da "Educação Midiática" nas escolas de ensino básico pode contribuir para a identificação desse tipo de notícias. Segundo [Auberry 2018], para que estudantes sejam capazes de distinguir entre fake news e notícias verdadeiras com eficácia, torna-se necessário incentivá-los a interagir com as fontes dessas notícias. Já o estudo [Musgrove et al. 2018] descreve como identificar notícias intencionalmente falsas em mídias virtuais e os recursos que professores podem utilizar para essa finalidade. Por fim, em [Nascimento 2020], busca-se compreender o fenômeno das fake news, relacionando-o com o conceito de mentira organizada.

O segundo grupo contém três trabalhos que, assim como o presente estudo, efetivamente utilizaram jogos como ferramentas educacionais para o desenvolvimento da capacidade crítica das pessoas quanto aos conteúdos digitais. Esses trabalhos foram comparados, conforme descrito na Tabela 1, segundo os seguintes critérios: idioma português (indica se as notícias que o jogo utiliza estão escritas na língua portuguesa), base atualizável (indica se a base de notícias pode ser atualizada), oferece suporte para mineração de dados e, por fim, o último critério indica se o jogo está em formato digital. A seguir esses trabalhos encontram-se brevemente descritos.

Dois dos três trabalhos mencionados no parágrafo anterior se baseiam na teoria da inoculação [Roozenbeek et al. 2019b, Roozenbeek et al. 2019a], originalmente proposta por William McGuire [McGuire 1964] que compara a divulgação de fake news com a propagação de uma epidemia viral. A base dessa teoria são tentativas de indução de atitudes de resistência à persuasão e à propaganda (seja ela enganosa ou não), de maneira análoga à imunização biológica. Ou seja, assim como as injeções que contêm uma dose enfraquecida de um vírus podem conferir resistência a futuras infecções por meio da produção de anticorpos, a teoria da inoculação postula que o mesmo efeito pode ser alcançado com 'anticorpos mentais', expondo as pessoas a uma versão enfraquecida de um argumento e refutando, posteriormente, esse mesmo argumento.

Em [Roozenbeek et al. 2019b], uma versão ativa da teoria da inoculação é proposta por meio da aplicação de um jogo denominado 'The Fake News Game'. Nesse jogo, inicialmente, os jogadores são divididos em grupos, mas somente um desses grupos recebe a tarefa ativa de criar notícias sobre uma questão fortemente politizada, usando táticas inerentes a diferentes tipos de produtores de fake news, conforme detalhado em [Marwick and Lewis 2017]. Logo após, realiza-se uma tarefa de identificação de fake news que envolve a leitura notícias fake e não fake, atribuídas aleatoriamente entre todos os jogadores. Os resultados obtidos por esse estudo fornecem informações preliminares, evidenciando que o poder de persuasão das fake news foi atenuado para o grupo de jogadores que realizou a tarefa de criação antes da tarefa de identificação de notícias fake. 
Uma outra forma de combater fake news utilizando gameficação foi proposta, por meio do jogo "Bad News Game"3, onde os jogadores assumem o papel de produtores de notícias e aprendem a dominar seis técnicas comumente utilizadas na produção de desinformação: polarização, invocação de emoções, disseminação de teorias da conspiração, debochar de pessoas on-line, desviar a culpa de determinada ação e utilizar contas falsas. Uma avaliação em larga escala desse jogo foi realizada com 15.000 participantes e evidências iniciais foram identificadas, indicando que a capacidade das pessoas de detectar e resistir à desinformação melhora após o jogo, independentemente da educação, idade, ideologia política e estilo cognitivo [Roozenbeek et al. 2019a].

Criado pela Factchekers.it para o evento Internacional Fact Checking Networking (IFCN), o jogo de RPG (i.e., Role-Playing Game) 'Cheque Isso' [de Abreu et al. 2018] foi desenvolvido a fim de incentivar o hábito de checagem de informações entre os jovens.

\begin{tabular}{|c|c|c|c|c|}
\hline Jogo & Idioma Português & Base Atualizável & Suporte para Mineração & Digital \\
\hline 'The Fake News Game' [Roozenbeek et al. 2019b] & & & & \\
\hline ‘Bad News Game’ [Roozenbeek et al. 2019a] & & & & $\mathrm{X}$ \\
\hline ‘Cheque Isso’ [de Abreu et al. 2018] & $\mathrm{X}$ & & & \\
\hline 'Jogo da Trilha' [JED adotado no presente trabalho] & $\mathrm{X}$ & $\mathrm{X}$ & $\mathrm{X}$ & $\mathrm{X}$ \\
\hline
\end{tabular}

Tabela 1. Comparação entre trabalhos relacionados

Em resumo, pode-se observar que, diferentemente do "Jogo da Trilha" proposto neste artigo, nenhum dos jogos indicados apresenta, simultaneamente, notícias escritas em Língua Portuguesa, base de notícias atualizável e recursos de apoio à análise de dados sobre o desempenho dos jogadores. Além disso, apenas um desses jogos é, de fato, digital.

\section{O Jogo da Trilha}

Acessível a partir da Memore-net ${ }^{4}$, o "Jogo da Trilha" propõe uma competição saudável entre os participantes e pode ser jogado individualmente ou em grupos de, no máximo, seis jogadores. Trata-se de um JED de tabuleiro que utiliza o mouse e o teclado do computador para que os jogadores acionem o dado e respondam às perguntas propostas, selecionadas aleatoriamente e sem reposição a partir de uma base de dados previamente configurada. As perguntas podem ser acompanhadas de imagens e são apresentadas na forma de múltipla escolha com até quatro opções de respostas.

Por estar integrado à Memore-net, o "Jogo da Trilha" pode ter seu conteúdo configurado pelo professor, além de ser capaz de coletar dados sobre o comportamento dos alunos durante as partidas ao longo do tempo. Os dados coletados podem ser posteriormente analisados pelo professor por meio de recursos de mineração de dados, a fim de apoiar o docente na avaliação discente e na identificação de lacunas de aprendizado. A Figura 1(a) apresenta, por meio de um diagrama de casos de uso [Bezerra 2016], uma visão simplificada das principais funcionalidades da Memore-net que são relevantes no contexto do presente artigo e que se encontram comentadas a seguir.

\footnotetext{
${ }^{3}$ https://www.getbadnews.com/\#play

${ }^{4}$ Plataforma colaborativa de apoio à aprendizagem que oferece recursos aos interessados em educação apoiada por computador para compartilhar experiências, realizar práticas de ensino-aprendizagem, aprender e aprimorar ações e políticas pedagógicas no uso das tecnologias da informação e comunicação em sala de aula [Passos et al. 2019a, Passos et al. 2019b]. Para detalhes, acessar http://memore-net. com.
} 
Para este trabalho, o "Jogo da Trilha" foi configurado de forma a desafiar os jogadores a identificar fake news. Assim, cada pergunta corresponde a uma afirmação cujas respostas possíveis são fake ou não fake. As perguntas são obtidas a partir de um conjunto de dados que contém, para cada pergunta, a data de publicação da notícia, a resposta correta e, se for o caso, alguma imagem associada. A escolha do conjunto de dados a ser utilizado é feita pelo professor, a partir do caso de uso UC01. Uma vez configurado, o JED pode ser jogado pelos alunos. Sempre que um aluno joga uma partida do jogo (UC02), os dados sobre o seu comportamento de utilização são armazenados no banco de dados do jogo e podem, posteriormente, ser acessados pelo docente por meio de consultas e técnicas de mineração de dados (UC03). Entre as técnicas disponíveis na Memore-net está o algoritmo Apriori (descrito em [Agrawal et al. 1993]) que, no contexto de aplicação deste trabalho, busca identificar regras de associação que mostrem a evolução da capacidade discente em diferenciar notícias fake das não fake.

A Figura 1(b) apresenta, um diagrama de classes da UML que contém uma visão parcial do modelo de dados conceitual simplificado (sem atributos) do banco de dados da Memore-net. Por meio deste modelo, percebe-se que as respostas fornecidas por cada aluno para cada pergunta em cada partida são armazenadas no banco de dados de forma a viabilizar uma posterior análise de desempenho. Cabe enfatizar que o caso de uso UC01 indicado na Figura 1(a) permite ao docente importar para o banco de dados do JED todas as perguntas a serem utilizadas nas partidas do referido JED.

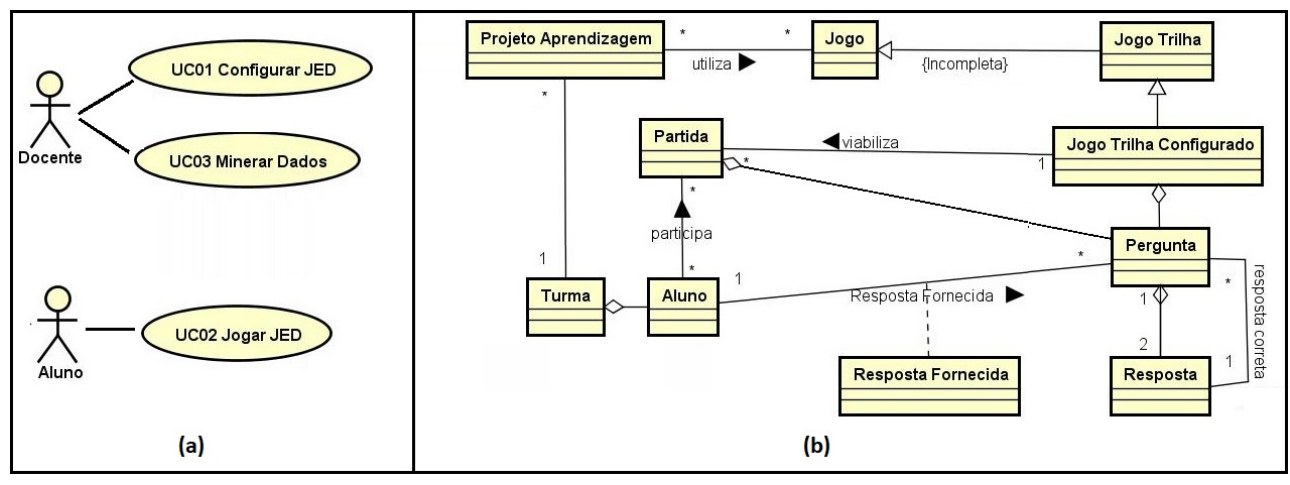

Figura 1. Modelos Parciais: (a) Funcional e (b) de Dados do "Jogo da Trilha".

A Figura 2 mostra exemplos de algumas telas do "Jogo da Trilha" configurado para o desafio de identificação de notícias fake. No item (a) está a interface onde os alunos escolhem o avatar desejado, informam sua idade e uma autoavaliação quanto à sua capacidade de identificar fake news. Para a autoavaliação, o aluno deve escolher um dentre os seguintes cinco níveis, organizados em ordem crescente de aptidão: noob (i.e., newbie, novato em inglês), iniciante, casual, avançado e proplayer. A nomenclatura adotada na denominação desses níveis procurou espelhar uma terminologia que fosse familiar aos alunos no universo dos jogos digitais modernos. Nos itens (b) e (c) encontram-se ilustradas, respectivamente, a interface principal do jogo e a tela apresentada ao final de cada partida, contendo o ranking dos jogadores com melhor desempenho até então.

\section{Estudo de Caso}

A fim de buscar evidências experimentais que indiquem que JED podem ser utilizados como ferramentas de apoio ao combate às fake news escritas na Língua Portuguesa, o 


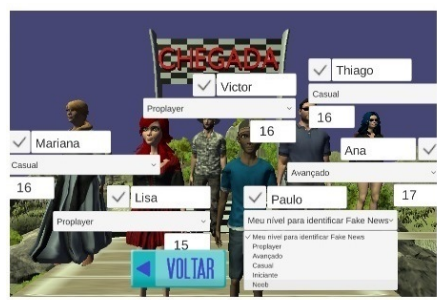

(a)

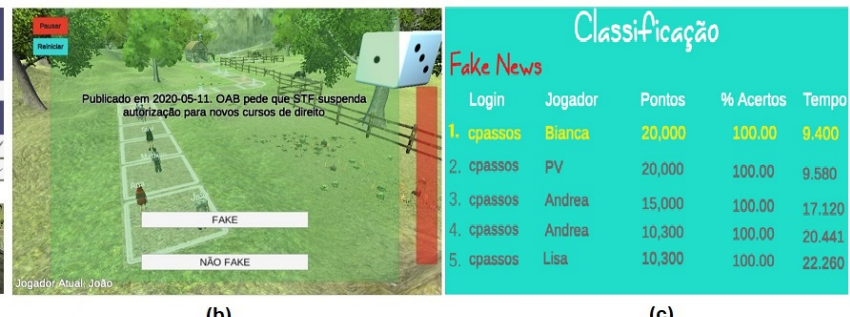

(b)

(c)

Figura 2. Telas do JED: (a) Configuração; (b) Principal; (c) Fim de partida

presente trabalho realizou um estudo de caso com o "Jogo da Trilha" descrito na Seção 3. O referido estudo foi desenvolvido junto a quarenta e três alunos na faixa de 14 a 21 anos (idade média de 15,3 anos e desvio padrão 1,1) do ensino médio de uma escola da rede privada de educação do município de Foz do Iguaçu no Paraná.

A metodologia do estudo de caso foi iniciada com uma reunião envolvendo as equipes diretiva e pedagógica da escola com a finalidade de planejar a aplicação do JED. Nesta reunião foram definidos docentes, turmas, horários e dinâmica de implementação.

Por conta do isolamento social imposto pela COVID-19, as orientações para os alunos sobre como utilizar o JED foram dadas com o apoio de uma sala virtual síncrona. Essas orientações foram organizadas em três grupos: (1) orientações sobre como acessar o JED, (2) orientações sobre como utilizar o jogo, e (3) orientações sobre como avaliar o JED. Entre as regras de utilização, três premissas básicas foram expostas aos alunos. Primeira: Cada aluno deveria jogar, no mínimo, duas partidas. Tal restrição teve como objetivo assegurar que todos os alunos pudessem ser avaliados de forma longitudinal. Segunda: A primeira e a última partida jogadas por cada aluno seriam consideradas para avaliar respectivamente os desempenhos inicial e final do referido estudante na identificação de fake news. Terceira: Cada discente deveria informar o nível de autoavaliação de sua capacidade em identificar fake news antes de iniciar cada partida no JED.

O conjunto de perguntas do "Jogo da Trilha" foi carregado com 600 notícias publicadas entre março de 2017 e maio de 2020, oriundas de três agências de checagem de fatos brasileiras (Lupa, Aos Fatos e AFP) e de duas mídias renomadas ( $G 1$ e R7). A Tabela 2 apresenta um resumo com características estatísticas do conjunto de notícias utilizado.

\begin{tabular}{|c|c|c|c|c|c|c|c|c|c|c|}
\hline & $\begin{array}{l}\text { Total de Notícias } \\
\text { (i.e., Perguntas) }\end{array}$ & $\begin{array}{l}\text { Notícias } \\
\text { sobre } \\
\text { Política }\end{array}$ & $\begin{array}{l}\text { Notícias } \\
\text { sobre } \\
\text { Economia }\end{array}$ & $\begin{array}{l}\text { Notícias } \\
\text { sobre } \\
\text { Saúde }\end{array}$ & $\begin{array}{l}\text { Notícias } \\
\text { sobre } \\
\text { Educação }\end{array}$ & $\begin{array}{l}\text { Notícias } \\
\text { sobre Tec- } \\
\text { nologia }\end{array}$ & $\begin{array}{l}\text { Notícias } \\
\text { sobre } \\
\text { Segurança }\end{array}$ & $\begin{array}{l}\text { Outras } \\
\text { Temáticas }\end{array}$ & $\begin{array}{l}\text { Média de } \\
\text { caracteres } \\
\text { por notícia }\end{array}$ & $\begin{array}{l}\text { Média de } \\
\text { palavras } \\
\text { por notícia }\end{array}$ \\
\hline Fake & 300 & 155 & 27 & 46 & 7 & 3 & 37 & 25 & 144,55 & 24,2 \\
\hline não Fake & 300 & 18 & 119 & 29 & 58 & 34 & 8 & 34 & 81,37 & 14,05 \\
\hline
\end{tabular}

Tabela 2. Estatísticas do conjunto de notícias utilizado

Diversos resultados relacionados ao desempenho discente puderam ser apurados após a utilização do JED. A Tabela 3 apresenta um resumo estatístico global desses resultados. Por meio dela, é possível perceber que todos os estudantes jogaram exatamente duas partidas, se limitando ao mínimo de partidas solicitado durante as orientações. Acredita-se que possa não ter ficado claro para os alunos que eles poderiam ter jogado mais partidas além do mínimo mencionado. Outro aspecto interessante é quanto ao percentual médio de acertos por partida. Pelo desvio padrão elevado, percebe-se uma heterogeneidade quanto à capacidade dos discentes em discernir entre notícias fake e não fake. 
IX Congresso Brasileiro de Informática na Educação (CBIE 2020)

Anais do XXXI Simpósio Brasileiro de Informática na Educação (SBIE 2020)

Similarmente, é possível identificar uma alta dispersão no tempo médio por partida.

\begin{tabular}{|l|c|}
\hline Aspecto analisado & Média apurada \pm desvio padrão \\
\hline Número de partidas por aluno & $2,00 \pm 0,00$ \\
\hline Tempo por partida (segundos) & $341,11 \pm 230.57$ \\
\hline Tempo de resposta por pergunta (segundos) & $9,97 \pm 4,70$ \\
\hline Percentual de acertos por partida & $69,50 \pm 29,00$ \\
\hline
\end{tabular}

Tabela 3. Resumo dos resultados obtidos

Um gráfico em barras contendo quantidades de erros e de acertos dos jogadores, distribuídos de acordo com a temática das perguntas, é apresentado na Figura 3(a). Por meio da leitura desse gráfico, é possível deduzir que notícias fake, relacionadas à tecnologia, são mais difíceis de ser identificadas.

A Figura 3(b) apresenta uma comparação entre a autoavaliação dos alunos em relação à sua capacidade em identificar fake news e os resultados efetivamente obtidos durante o jogo ${ }^{5}$. Percebe-se uma clara divergência entre as impressões dos discentes quanto à sua capacidade de acerto e o seu desempenho apurado por meio do jogo.

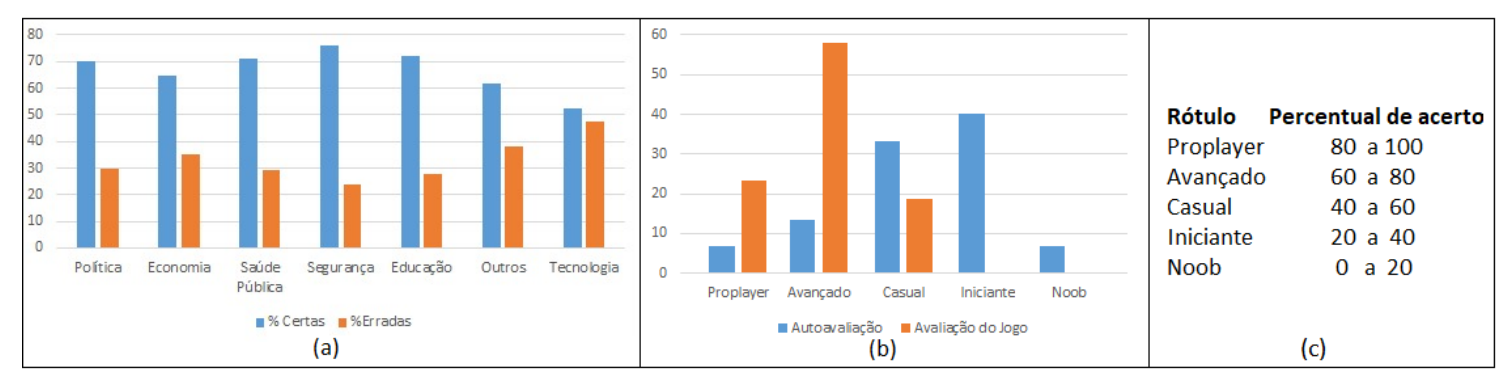

Figura 3. (a) Acerto/erro por tema (b) Autoavaliação e desempenho real (c) Faixas

A Figura 4(a) ilustra o desempenho dos alunos nas duas partidas. Neste caso, percebe-se um aumento no percentual de acertos e no tempo médio de resposta, o que denota tanto uma melhoria na capacidade de identificação de fake news quanto uma análise mais atenta e criteriosa das notícias. Algumas regras de associação foram identificadas com a aplicação do algoritmo Apriori e três exemplos delas estão expostos na Figura 4(b). O termo consequente das três regras apresentadas (i.e.: capacidade crítica aumentou) refere-se à evolução da capacidade discente em diferenciar notícias fake das não fake de uma partida para outra. Essas regras indicam, com elevada confiança, que na primeira partida, os alunos classificados no nível avançado pelo jogo, bem como discentes que se autoavaliam casuais ou iniciantes, tendem a aumentar suas capacidades críticas.

Outra observação que merece destaque foi a capacidade dos alunos em perceber como fake algumas notícias cujo teor reflete situações absurdas, como a retratada na notícia "Publicado em 11/09/2018. Jovem se esfaqueia para provar que facada de Bolsonaro foi falsa e acaba morrendo.". Dos vinte e oito alunos que foram confrontados com esta notícia apenas um deles (3\%) errou, ao indicá-la como não fake.

Após o encerramento da atividade de utilização do JED, cada estudante respondeu a um instrumento de avaliação do jogo cujas perguntas (expressas por meio de afirmações)

\footnotetext{
${ }^{5}$ A classificação dos resultados pelo jogo foi obtida a partir da discretização do número médio de acertos de cada aluno conforme as faixas de valores indicadas na Figura 3(c).
} 


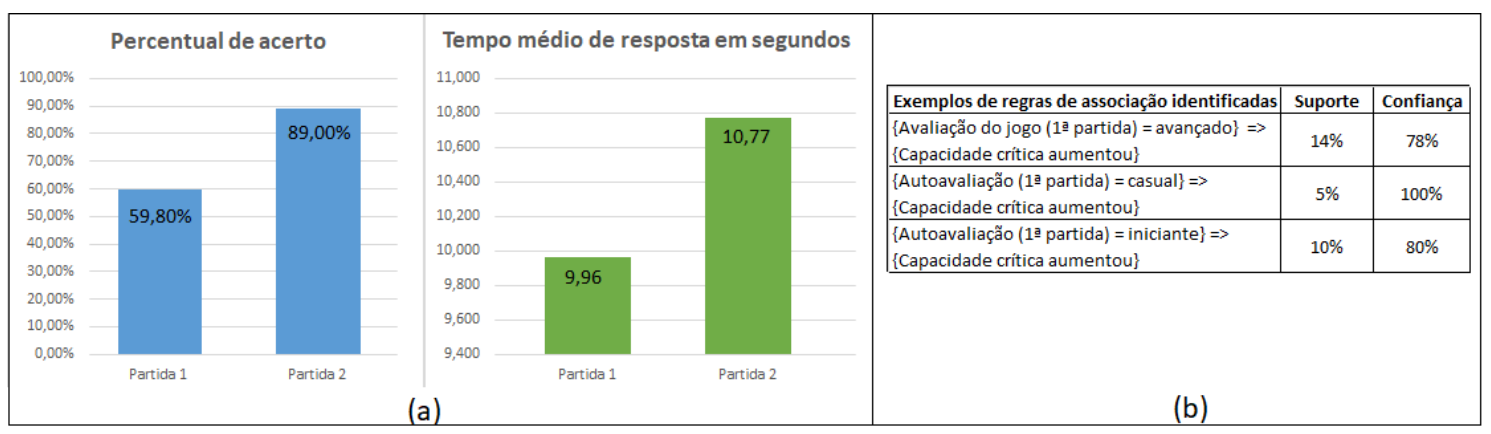

Figura 4. (a) Desempenho dos alunos (b) Exemplos de regras de associação.

foram adaptadas a partir da escala motivacional para materiais instrucionais utilizada por [Savi et al. 2011]. As perguntas foram organizadas em dimensões conforme ilustrado na Tabela 4. A fim de determinar o grau de concordância com as afirmações das dimensões avaliadas, cada aluno atribuiu uma nota da seguinte escala Likert: -2 (discordo fortemente), -1 (discordo parcialmente), 0 (não concordo nem discordo), +1 (concordo parcialmente), +2 (concordo totalmente).

\begin{tabular}{|c|l|l|}
\hline Dimensão & Descrição & Exemplo de pergunta \\
\hline Atenção & Obtenção e a manutenção da atenção na dinâmica do jogo. & $\begin{array}{l}\text { A variação, na forma/conteúdo ajudou } \\
\text { a me manter atento ao jogo. }\end{array}$ \\
\hline Relevância & Consiste na avaliação da importância do conteúdo. & O conteúdo do jogo é relevante. \\
\hline Imersão & $\begin{array}{l}\text { Refere-se ao envolvimento, pleno e total, como o jogo, por } \\
\text { exemplo, diminuição a consciência às ocorrências do entorno, } \\
\text { alteração na noção de tempo, entre outros. }\end{array}$ & $\begin{array}{l}\text { Eu não percebi o tempo passar en- } \\
\text { quanto jogava, quando vi o jogo aca- } \\
\text { bou. }\end{array}$ \\
\hline Interação Social & $\begin{array}{l}\text { Menuração do sentimento de cooperação, competição, co- } \\
\text { nexão com outros jogadores, entre outros. }\end{array}$ & $\begin{array}{l}\text { Percebi que o jogo permite interagir } \\
\text { com outras pessoas. }\end{array}$ \\
\hline Desafio & $\begin{array}{l}\text { Avaliação da compatibilidade dos desafios do JED com } \\
\text { o nível de habilidades do jogador, ou seja, refere-se à } \\
\text { mensuração do quanto o jogo é desafiador para o público alvo. }\end{array}$ & $\begin{array}{l}\text { Este jogo é adequadamente desafiador } \\
\text { para mim, as tarefas não são muito } \\
\text { fáceis nem muito difíceis. }\end{array}$ \\
\hline Divertimento & $\begin{array}{l}\text { Mensuração do quanto a partida foi prazerosa e divertida, me- } \\
\text { recendo a recomendação do JED aos amigos. }\end{array}$ & $\begin{array}{l}\text { Gostaria de utilizar este jogo nova- } \\
\text { mente. }\end{array}$ \\
\hline Competência & $\begin{array}{l}\text { Refere-se à avaliação do quanto o jogo apoia o desenvolvi- } \\
\text { mento de habilidades do jogador. }\end{array}$ & $\begin{array}{l}\text { Conseguiria melhorar a capacidade de } \\
\text { reconhecer FakeNews. }\end{array}$ \\
\hline
\end{tabular}

Tabela 4. Dimensões do JED avaliadas - Adaptação de [Savi et al. 2011].

A Tabela 5 sumariza os dados do questionário aplicado durante a etapa de avaliação do jogo pelos alunos. Na primeira linha são apresentadas as dimensões avaliadas. A segunda apresenta as médias dos graus de concordância informados pelos alunos ao responder às perguntas das respectivas dimensões.

\begin{tabular}{|l|c|c|c|c|c|c|c|}
\hline Dimensão & Atenção & Relevância & Imersão & Interação Social & Desafio & Divertimento & Competência \\
\hline Média \pm Desvio Padrão & $0,46 \pm 1,10$ & $1,13 \pm 0,96$ & $0,38 \pm 1,26$ & $-0,44 \pm 1,41$ & $0,69 \pm 1,26$ & $0,75 \pm 1,19$ & $1,31 \pm 0,79$ \\
\hline
\end{tabular}

\section{Tabela 5. Médias dos graus de concordância das dimensões avaliadas}

Ao analisar os resultados na Tabela 5, percebe-se que, com exceção da "Interação Social", todas as dimensões tiveram avaliação média acima de zero, indicando, portanto, uma tendência de avaliação positiva dos aspectos analisados. Cabe ressaltar, no entanto, que os valores de desvio-padrão apresentados mostram uma certa divergência entre as opiniões. A baixa avaliação dos aspectos ligados à interação social era esperada, uma vez que a versão do jogo utilizada não viabilizava a realização de partidas com jogadores simultâneos. Por fim, duas dimensões se destacam pela boa avaliação: "Relevância"e "Competência". Enquanto a primeira reflete a consciência discente com relação à im- 
portância do conteúdo tratado pelo JED, a segunda revela o reconhecimento dos alunos quanto ao potencial do jogo em aumentar sua capacidade em identificar fake news.

Após a aplicação do instrumento de avaliação, os alunos emitiram alguns feedbacks para melhoria do jogo (e.g. "[...] o jogo poderia ser um pouco mais curto. Como o jogo fala de notícias, um tempo de duração muito grande fica cansativo". Os estudantes também comentaram sobre quais características os levavam a identificar as notícias falsas (e.g. "Na maioria das notícias falsas existiam muitos erros gramaticais e ortográficos e também muitas delas eram absurdas, [...] tinham pouquíssimas chances de serem reais.”).

De uma forma geral, os resultados observados neste estudo contêm evidências que apontam para uma resposta positiva à questão de pesquisa quanto à possibilidade de uso de $J E D$ para capacitação discente na identificação de fake news escritas em Português.

\section{Considerações Finais}

Uma das formas de combate às fake news é capacitar pessoas para identificá-las por meio de JED. Entretanto, os JED utilizados não dispõem de notícias escritas em Língua Portuguesa. Com o objetivo de suprir esta lacuna, o presente artigo propôs uma versão do "Jogo da Trilha" que exercita a identificação de fake news escritas em Português, além de oferecer suporte para mineração e análise de dados sobre o desempenho de seus jogadores. Um estudo de caso com o "Jogo da Trilha" foi aplicado junto a quarenta e três alunos de ensino médio, onde foi possível perceber uma clara divergência entre as impressões iniciais dos discentes quanto à sua capacidade de acerto e o seu desempenho apurado por meio do jogo. Além disso, destaca-se a evolução do desempenho individual dos alunos nas duas partidas, evidenciada pelo aumento no percentual de acertos, o que denota uma melhoria do desempenho discente de uma partida para outra. Cabe ressaltar que, segundo a avaliação dos alunos, o JED proposto apresenta um elevado grau de adequação ao seu propósito. Entre os trabalhos futuros, pretende-se desenvolver uma versão que permita múltiplos jogadores participarem em rede, melhorar o design do JED, realizar novos estudos de caso, além de incorporar suporte tutorial ao reconhecimento de fake news.

\section{Agradecimentos}

Ao Colégio Bertoni de Foz do Iguaçu/PR e às suas equipes diretiva, pedagógica e docente, além de seus discentes, pela participação na pesquisa.

\section{Referências}

Agrawal, R., Imieliński, T., and Swami, A. (1993). Mining association rules between sets of items in large databases. SIGMOD Rec., 22(2):207-216.

Auberry, K. (2018). Increasing students' ability to identify fake news through information literacy education and content management systems. The Reference Librarian, 59(4).

Bezerra, E. (2016). Princípios de Análise e Projeto de Sistema com UML. R.J.: Elsevier.

de Abreu, P. M. R., Berwanger, P. M., and Costa, R. B. (2018). Gameficação e as fakenews: uma análise do jogo cheque isso! PROJEÇÃO E DOCÊNCIA, 9(2):167-177.

Francesco, N. N. and Leone, S. D. (2020). 1. educação midiática contra"fake news". Revista Científica UMC, 5(1). 
Freire, P. and Goldschmidt, R. (2020). Combatendo fake news nas redes sociais via crowd signals implícitos. In Anais do XVI ENIAC, pages 424-435, RS, Brasil. SBC.

Freire, P. M. S. and Goldschmidt, R. R. (2019). Uma introdução ao combate automático às fake news em redes sociais virtuais. In Tópicos de Gerenciamento de Dados e Informação, 34th SBBD, pages 38-67, Fortaleza, CE, Brazil. SBC.

Marwick, A. and Lewis, R. (2017). Media manipulation and disinformation online. New York: Data \& Society Research Institute.

McGuire, W. J. (1964). Some contemporary approaches. In Berkowitz, L., editor, Advances in experimental social psychology, volume 1, pages $191-229$. Elsevier.

Mejova, Y. and Kalimeri, K. (2020). Advertisers jump on coronavirus bandwagon: Politics, news, and business. ArXiv, abs/2003.00923.

Musgrove, A. T. et al. (2018). Real or fake? resources for teaching college students how to identify fake news. College \& Undergraduate Libraries, 25(3):243-260.

Nascimento, C. E. G. (2020). Fake news, mentira organizada e educação:uma reflexão a partir do pensamento de hannah arendt. Revista Docência e Cibercultura, 4:243-263.

Passos, C., Fernandes, I., and Goldschmidt, R. (2019a). Elaboração e avaliação de projeto de aprendizagem apoiado em jogos educacionais digitais: Um relato de experiência com alunos em alfabetização. In SBIE, volume 30, page 674.

Passos, C. A., Fernandes, I., and Goldschmidt, R. R. (2019b). Um ambiente para coleta, integração e mineração de dados sobre o comportamento de estudantes na utilização de jed e seu desempenho em avaliações escolares. In SBGAMES.

Paz, D. P. et al. (2018). Desenvolvimento e avaliação de um jogo digital educacional sobre aspectos socioculturais de países hispano falantes. In SBIE, volume 29, page 795.

Roozenbeek et al. (2019a). Fake news game confers psychological resistance against online misinformation. Palgrave Communications, 5(1):65.

Roozenbeek, J. et al. (2019b). The fake news game: actively inoculating against the risk of misinformation. Journal of Risk Research, 22(5):570-580.

Savi, R., Wangenheim, C., and Borgatto, A. (2011). Um modelo de avaliação de jogos educacionais na engenharia de software. SBES 2011.

Shu, K., Sliva, A., Wang, S., Tang, J., and Liu, H. (2017). Fake news detection on social media: A data mining perspective. SIGKDD Explor. Newsl., 19(1):22-36.

UNESCO (2016). Marco de Avaliação Global da Alfabetização Midiática e Informacional (AMI): disposição e competências do país. Cetic.br.

UNESCO (2019). Manual para Educação e Treinamento em Jornalismo. UNESCO.

Zhou, X. et al. (2019). Fake news: Fundamental theories, detection strategies and challenges. In WSDM '19, pages 836-837, NY, USA. ACM. 